\title{
Classical modernist planning and the menace of automobile dependence in cities: the case of Abuja, Nigeria
}

\author{
S. Y. Razak \\ School of Built Environment (SOBE), University of Salford, UK
}

\begin{abstract}
Unequivocally, it has become increasingly clear that the approach of Classical Modernist planning (CMP) that prevailed after World War II emphasizes huge permissivity for low-density sprawling suburban development and the meteoric rise of motorization in cities. The implicit "predict and provide" approach of building and expansion of roads to ease congestion continued to skew investments on transportation towards permitting private automobile ownership and use at the expense of public transportation. As a result, the inherent menaces of automobile dependence are continuing in cities especially in the Global South including Abuja, Nigeria.

This study has illustrated that the prevailing CMP system in Abuja, has continually spurred and fuelled the growth of suburbia. Consequently, the emerging automobile dependent mobility pattern is indeed plagued with the challenges of $\mathrm{CO}_{2}$ emissions, traffic congestion, and related man-hour and fuel wastage. This study reveals that by institutionalizing spatial planning strategies as BRT, TOD and congestion pricing it is possible to transform sprawling automobile dependent cities to smart compact transit dependent cities. Hence, the implicit $\mathrm{CO}_{2}$ emissions and traffic congestion challenges of man-hour and fuel wastage on the AYA route in Abuja is retrofitted, and the ecological and carbon footprints is dwarfed.
\end{abstract}

Keywords: spatial planning, automobile dependence, $\mathrm{CO}_{2}$ emissions, classical modernist planning (CMP), transit oriented development (TOD), bus rapid transit (BRT), congestion pricing. 


\section{Introduction}

Globally, urbanization has continued to create agglomeration in cities with implicit increasing ecological and carbon footprint from the huge consumerism pattern. With the deficit of the requisite institutional capacities and policy response, the increasing urbanization has led to phenomenal level of urban sprawl/suburbanization expressed in overly extensive spatial form that has increased travel distance/Vehicle Kilometre Travelled (VKT) between employment area in the core-city and suburban residential areas. This consumption pattern is expressed in several ways, these include the increasing demand for mobility as a result of increasing income level, and importantly because mobility is a critical enabler of economic development. Consequently, this demand for mobility has overwhelmed most cities and has permitted automobile-dependent mobility pattern with related consequences as $\mathrm{CO}_{2}$ emissions and traffic congestion problems of man-hour and fuel wastage [1-6].

More worrisome is that the phenomenal growing trend of suburbanization, demand for mobility and the growth of automobile dependence closely mimic the trend of urbanization and it is feared that these trend will not only leverage cities' carbon footprint, but also exacerbate the dysfunctional mobility pattern. With prevailing CMP system, agglomeration and suburbanization have grown phenomenally. In addition the implicit predict and provide engineering solution to transportation challenges has permitted building and expansion of highways as exemplified in North American cities [7, 8], rather than huge investment in public transportation exemplified in Curitiba-Brazil, Bogota-Columbia and Rotterdam-the Netherlands. Several studies have illustrated the reduction in urban sprawl and creation of more transit oriented urban communities [7, 9, 10], can permit remarkable reduction in automobile dependence and suburbanization. This prevailing engineering solution of the CMP paradigm in Abuja has increasingly created enabling environment for the growth of suburban areas of Nyanya-Karu, Kubwa-Bwari and Kuje-Gwagwalada axes, and this has permitted automobile dependence with less investment in public transportation. As a result daily motorized trips are high and take place via private automobile and fragmented, un-reliable polluting mini-buses that strongly contribute to $\mathrm{CO}_{2}$ emissions, traffic congestion and related challenges of man-hour and fuel wastage.

\subsection{Scope}

This study centres on the analysis of spatial planning strategy as tool for transforming the existing Classical Modernist Planning (CMP) system in Abuja and the implicit prevailing $\mathrm{CO}_{2}$ emissions and traffic congestion related challenges stemming from the huge automobile-dependent mobility pattern. With focus on the commuting volume via private automobile and mini-buses between the suburban residential area of Nyanya-Karu axis along the AYA Route, and the core-city employment area of Abuja (see Figure 1). 


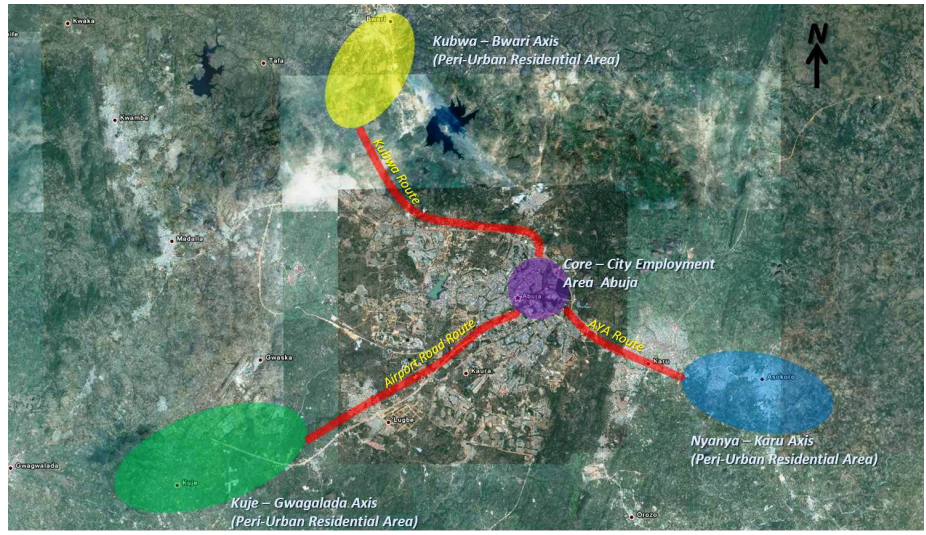

Source: [11].

Figure 1: $\quad$ Sprawling suburbanizing peri-urban areas of Abuja.

\section{Methodology}

The study relies on both Primary and Secondary data. The Primary data were acquired from direct personal observation, photo recording and interview sessions with transport user groups (commuters and drivers), transport owner groups: National Union of Road Transport Workers Nig. Ltd. (NURTW), Abuja Urban Mass Transport Company Ltd. (AUMTCO), and Self-Employed Commercial Drivers Association Nig. Ltd. (SECDA); Practitioners in Federal Capital Development Authority (FCDA) Urban Planning Department, Satellite Towns Development Agency (STDA) Planning and Housing Divisions, FCT Transport Secretariat, FCT Directorate for Road Traffic Services (DRTS), Federal Road Safety Commission (FRSC), and Federal Ministry of Environment. The total number of interviews conducted equals 18 .

\section{The role of CMP in creating automobile dependence in cities}

Increasingly, there has been consensus on the un-sustainability of the present unprecedented level of automobile usage in cities because of its inherent challenges as $\mathrm{CO}_{2}$ emission congestion, and particulate matter air pollution. Unequivocally, this existing quagmire has been created by the existing Classical Modernist Planning paradigm (Master Plan). This paradigm is characterized by the "Predict and Provide" engineering solution of road building and expansion, low-density development, dispersed urban forms, expert-driven technocratic activities, single-use zoning, and rigid standards/ regulations. More worrisome is that this paradigm has permitted sprawl and suburbanization which has continually increased the distance between suburban areas and the core-city.

In line with the relentless pragmatism of pursuing the predict and provide engineering solution that characterizes the CMP system, roads are continually 
built and expanded to address these transportation challenges, and this fuels the trend of sprawl/suburbanization [10,12]. Empirical evidence has shown that traffic do not behave like liquid that retain its volume in a given space, but rather like gas that expand over any given space so provided [13, 14]. As such this engineering solution which skews transportation investments towards building more roads largely induces more traffic and soon after the expansion phase the traffic challenges that ensue depict as though nothing was done earlier. According to Newman and Kenworthy [14] automobile dependence is inevitable in this un-sustainable scenario of traffic engineering, as it sets in motion vicious circle of self-fulfilling prophecy of congestion and more road building.

These challenges have remained deeply rooted in the fabric of cities globally because these form of planning spread to all corners of the world in the $20^{\text {th }}$ century through the processes of colonialism, market expansion, international planning consultancies and intellectual exchange of planning values peculiar to solving the challenges of European cities [10].

This explains the influences and diffusion of CMP ideas to most of SubSaharan Africa. Many master plans and zoning schemes in Nigerian cities including Abuja today maintain this geographic density distinction devoid of density mix, single-use areas devoid of functional mix and permissive mobility of building and expansion of roads [15, 16]. Planning Laws and Zoning Ordinances, in many cases today is exact replica of those in Europe and UK in the early $20^{\text {th }}$ century and is still enforced as under colonial autocratic rules.

Today, Abuja is faced by challenges of dysfunctional transport system characterized by automobile proliferation and related externalities of $\mathrm{CO}_{2}$ emission, traffic congestion and related challenges of fuel and man-hour wastage.

\section{The role of spatial planning strategies in reducing transport-related $\mathrm{CO}_{2}$ emissions in cities}

The imperatives of sustainable urban development in cities globally necessitated the quest for new urban planning paradigm as spatial planning that emphasize the "coordination or integration of the spatial dimension of sectoral policies through a territorial based strategy" by establishing better coordination on territorial impacts "horizontally across different sectors, vertically among different levels of jurisdiction, and geographically across administrative boundaries" [17]. This paradigm allow for situation-specific broad range approaches, that is capable of addressing the challenges created in cities globally as a result of international borrowings of the "off- the-shelf" CMP system.

Put more succinctly, this new order of spatial planning seeks to change urban planning from the existing quagmire of restrictive bureaucratic exercise that constraints development, to a more pro-development scenario where urban planning system will be proactive rather than reactive. The adoption of strategic solution as building valid TOD, integrated public transportation as BRT and implementing Congestion pricing can be used to address the huge externalities (congestion, particulate matter pollution and GHG emissions) from automobile- 
centered mobility pattern in cities and climate change action at the urban level [4, 6, 18-21].

The city centre planning in Sheffield, Curitiba, Bogota, Guangzhou, and the implementation PPG 13 in the UK exemplifies the application of spatial planning centered on encouraging the use of transit public transport and mixed development along its corridor. With this automobile centered mobility is transformed. This is coupled with the integration of walking and cycling infrastructure within the corridor, and park and ride facility to optimize transit operation [17]. In addition, strategy for containing congestion for road users is also put in place. Here, we see strong focus on using spatial planning to effectively support the provision of transit services, reduced private automobile usage, and smart compact transit-oriented development and making the city more sustainable.

\section{Results and discussions}

Data collected from the various methods are analysed to reveal the existing challenges and potential solutions. The theme of the analysis include existing CMP, Urbanization trend, Suburbanization (overly extremely spatial form), statutory capital expenditure on building and expansion of roads/highways, menaces of automobile dependence and TOD and existing policy on affordable housing on peri-urban area of Nyanya-Karu.

\subsection{Existing classical modernist planning (CMP) system in Abuja}

The existing planning system in Abuja is the CMP (master plan), with the blueprint document prepared in 1979. Available data with the FCDA Urban Planning Department revealed that the Master Plan document has never had a comprehensive review except for partial review of the Central Area district and Landuse Plan in 2006 and 2008 respectively (30 years after inception). This however explains the deficit in the capacity of the plan to respond to the challenges of growing urbanization and suburbanization. A desk review of the Abuja Master Plan [22] document show that its contents is devoid of urban planning strategies directed at stemming $\mathrm{CO}_{2}$ emissions, addressing the challenges of climate change and achieving sustainable development goals.

The practitioner in the Urban Planning department opined that the existing planning philosophy and institution need to be leveraged to permit sectoral integration that is directed at achieving transit dependent mobility pattern. And that the new system is to reflect strongly coupled high density development along transit corridors and within peri-urban areas, as this will be a valid approach at reversing automobile dependent system and all related challenges.

\subsection{Expansion of highways}

The structure of expenditure on transportation sector (road building and expansion, public transport and other road-related infrastructure project) in the FCT Abuja is illustrated below in Figure 2. 


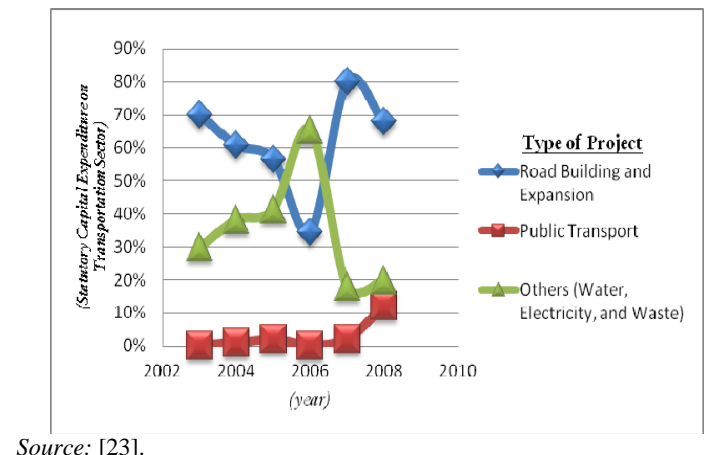

Figure 2: $\quad$ FCT-Abuja statutory capital expenditure on Transportation Sector (2003-2008).

According to available record, until 2008 when the LRT project was conceived, funding for building and expansion of roads/highways has been prioritised and sustained, while funding for public transport has been abysmally low. The predict and provide engineering solution of the existing CMP system in Abuja is here illustrated by the huge gap between capital expenditure of the FCT on the building and expansion of highways, and public transport infrastructure. Practitioners in the FCT Transport Secretariat opined that the philosophy of the FCT budget need to be redesigned to reflect priority to public transport projects as this will encourage investments in transit infrastructure and de-emphasize road building and expansion that induces more traffic and related challenges of $\mathrm{CO}_{2}$ emissions and traffic congestion.

\subsection{Automobile dependent mobility pattern in Abuja}

Data on passenger and vehicle traffic conducted by the FCT Transportation Secretariat (2008), and the Author in 2011 is illustrated in Figures 3 and 4.

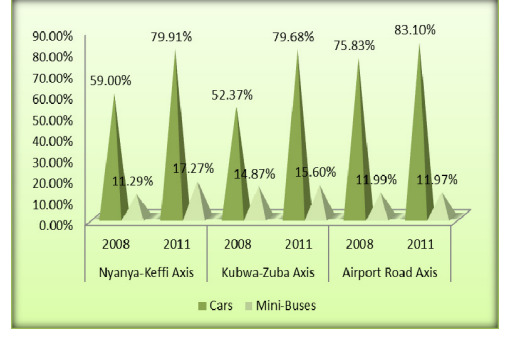

Source: [24]

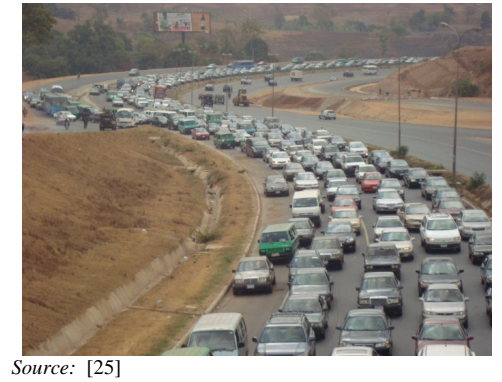

Figure 4: Traffic jam on Nyanya-Karu highway, Abuja. vehicular traffic (cars and mini-buses).

Figure 3: Trend of growth of 
This data reveal that the volume of vehicular traffic inflow into the core-city Abuja on the Nyanyan-Karu, Kubwa-Zuba and Airport Road routes. And thus illustrate an automobile dependent mobility system in Abuja.

\subsection{Reducing transport-related $\mathrm{CO}_{2}$ emissions and traffic congestion challenges with the application of spatial planning strategies in Abuja}

The analyses in this section reveal the $\mathrm{CO}_{2}$ emissions and traffic congestion levels in the existing scenario and also illustrate the potential savings achievable when spatial planning strategies; Transit (BRT), Transit Oriented Development (TOD), and Congestion Pricing in the new scenario are implemented.

\subsection{Transit (Bus Rapid Transit - BRT)}

High capacity articulated BRT system could replace the existing mobility pattern comprises of commute via small-capacity, tightly-packed, polluting and unreliable mini-buses and private automobile which grew 9.81\% and $12.09 \%$ respectively since 2008. Quite astonishingly, these annual rates of increases closely mimic the annual rate of population growth (9.3\%), by this, existing scenario of automobile dependence need to be reduced.

\section{Transforming the existing mobility pattern on AYA Route to a transit system (BRT)}

The existing 4297 mini-buses (18 passengers) will therefore be replaced by 484 new articulated buses (160 passengers). In addition, the existing modal share within the major daily motorized modes; mini-buses - 4297 (15.25\%) and Private automobile $-23,874$ (84.7\%) will have to be re-calibrated and re-arrange to reflect a new modal share where new articulated buses (BRT) will be $55 \%$, and the private automobile will be $45 \%$.

\section{1 $\mathrm{CO}_{2}$ emissions levels in the existing and proposed scenario}

Using the standard of $2.4 \mathrm{~kg} \mathrm{CO}$ (petrol) and $2.7 \mathrm{~kg} \mathrm{CO}$ (diesel) emission for every litre of fuel [26] used by mini-buses and private automobile vehicle, the $\mathrm{CO}_{2}$ emission level of AYA route is analyzed in this section (see Table 1).

Table 1: $\quad$ Computing for $\mathrm{CO}_{2}$ emissions.

\begin{tabular}{|l|c|c|c|c|}
\hline \multirow{2}{*}{ Scenario } & \multicolumn{2}{|c|}{ Bus System } & \multicolumn{2}{c|}{ Private Automobile } \\
\cline { 2 - 5 } & Mode & $\begin{array}{c}\text { Yearly } \mathrm{CO}_{2} \\
\text { Emission (Kg) }\end{array}$ & Mode & $\begin{array}{c}\text { Yearly } \mathrm{CO}_{2} \\
\text { Emission }(\mathrm{Kg})\end{array}$ \\
\hline $\begin{array}{l}\text { Existing } \\
\text { Scenario }\end{array}$ & $\begin{array}{c}\text { Old Bus - 4297 buses } \\
(15.25 \% \text { of Daily } \\
\text { Motorized trips) }\end{array}$ & $20,282,512.389$ & $\begin{array}{c}84.75 \% \text { (Daily } \\
\text { motorized trip) } \\
=23,874 \text { (Cars) }\end{array}$ & $70,711,811.2137$ \\
\hline $\begin{array}{l}\text { Proposed } \\
\text { Scenario }\end{array}$ & $\begin{array}{c}\text { New Bus - (4297 old } \\
\text { buses replaced by 484 } \\
\text { new articulated buses }\end{array}$ & $7,831,282.5$ & $\begin{array}{l}45 \% \text { (Daily } \\
\text { motorized trip) } \\
=12,606 \text { cars }\end{array}$ & $37,337,400.1937$ \\
\hline Savings & Savings $\left(\mathrm{kgCO}_{2}\right)$ & $12,451,229.88$ & & $33,374,411.02$ \\
\hline
\end{tabular}


When these savings are aggregated for the new transit-dependent mobility and reduced private automobile usage scenario, the $\mathrm{CO}_{2}$ emission level of the existing scenario is reduced from $90,994,323.6027 \mathrm{Kg} \mathrm{CO}_{2}$ to $45,168,682.6937$ $\mathrm{Kg} \mathrm{CO}_{2}$. This indicates a remarkable saving from the application of the BRT spatial planning strategies. Undoubtedly, this saving will progressively improve as the efficiency of the new transit regime improves and attract choice riders from private automobile mode.

\subsection{Fuel usage levels in the existing and proposed scenario}

Using the per capita fuel consumption of non-congestion non-peak period of 0.19444 litre litres per passenger and congestion peak period of 0.24305 litre per passenger, the total yearly fuel usage for the existing mini-buses was computed. Similarly, using 1.28553616 litre per passenger for private automobile trips, the yearly fuel usage was computed (see Table 2).

Table 2: $\quad$ Computing for fuel consumption.

\begin{tabular}{|c|c|c|c|c|}
\hline \multirow[t]{2}{*}{ Scenario } & \multicolumn{2}{|c|}{ Bus System } & \multicolumn{2}{|c|}{ Private Automobile } \\
\hline & Mode & $\begin{array}{c}\text { Yearly Fuel Usage } \\
\text { (litres) }\end{array}$ & Mode & $\begin{array}{c}\text { Yearly Fuel Usage } \\
\text { (litres) }\end{array}$ \\
\hline $\begin{array}{l}\text { Existing } \\
\text { Scenario }\end{array}$ & $\begin{array}{c}\text { Old Bus }-4297 \text { buses } \\
\text { (15.25\% of Daily } \\
\text { Motorized trips) }\end{array}$ & $8,451,046.8288$ & $\begin{array}{c}84.75 \% \text { (Daily } \\
\text { motorized trip) }= \\
23,874 \text { (Cars) }\end{array}$ & $29,463,254.6724$ \\
\hline $\begin{array}{l}\text { Proposed } \\
\text { Scenario }\end{array}$ & $\begin{array}{c}\text { New Bus - (4297 old } \\
\text { buses replaced by } \\
484 \text { new articulated } \\
\text { buses }\end{array}$ & $2,900,475$ & $\begin{array}{c}45 \% \text { (Daily } \\
\text { motorized trip) }= \\
12,606 \text { cars }\end{array}$ & $15,557,250.0824$ \\
\hline \multirow[t]{2}{*}{ Savings } & Savings (Litres) & $5,550,571.828$ & & $13,906,004.59$ \\
\hline & Savings (\#) & N 538,405,467.3 & & 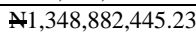 \\
\hline
\end{tabular}

When these savings are aggregated for the new transit-dependent mobility and reduced private automobile usage the fuel usage level of the existing scenario is reduced from $37,914,301.5012$ to $18,457,725.084$ litres of fuel. This indicates a remarkable saving from the application of the spatial planning strategies.

\subsection{Man-hour wastage in existing and proposed scenario}

In line with data on the structure of the occupational and income class of passengers on the existing mini-bus system and private automobile, the total income loss due to man-hour wastage in congestion is analyzed in this section When these savings are aggregated for the new transit-dependent mobility and reduced private automobile usage the man-hour loss level of the existing scenario is reduced from 11,015,520 hours $(\mathrm{N} 1,630,795,662.2)$ to 2,346,599 hours (N488,899,922).

\subsection{TOD and FCT STDA policy on affordable housing in peri-urban areas}

The FCT STDA has started implementing the affordable housing programme in peri-urban areas including the Nyanya-Karu axis. This axis is characterized by 
both planned and un-planned development. Data from direct personal observation in line with satellite imageries reveals that the planned areas cover approximately 32\% with density of 160 persons per hectare and un-planned area covering 68\% with density of 195 persons per hectare. Though the latter reflect intensity of development, they constitute overly extensive, tightly-packed, spontaneous, un-regulated haphazard un-hygienic living environment. And the locations of this site are not tied to any transit corridor.

When this existing density is compared to 294 persons per hectare density exemplified along the transit corridors and within the nodes in Curitiba [27], the existing density in Nyanya-Karu axis is at best medium density development. With the continuing trend of automobile dependent mobility pattern, as the only commute option for these residents, the level of transport-related $\mathrm{CO}_{2}$ emissions and traffic congestion challenges will no doubt soar.

The consensus of opinion of practitioner in FCDA and STDA indicates that the solution lies in identification of potential nodes with TOD character in implementing the affordable housing programme along AYA route and the periurban settlement of the Nyanya-Karu axis.

\subsection{Congestion pricing}

Practitioners in the FCT Transport Secretariat, DRTS and FRSC opined that when the transit regime becomes operational in Abuja, and transit services are optimal enough to attract choice riders from other modes, the congestion pricing regime will become desirable.

The proposed congestion pricing/charging system will be based on the defined Traffic Restricted Zone (TRZ) to circumscribe the Federal Capital City Abuja (City-Core), whereby entering the TRZ will require pay permit or penalty for entrants. The Automatic Number Plate Recognition (ANPR) technology will be adopted, and this will rely on licensed plate of private automobile vehicles and cameras with ANPR technology installed at designated location around the perimeter of the TRZ. Based on daily, weekly, or annual passes/permit into the TRZ, the drivers' number plate is registered as authorized vehicles on the data base for the time period requested. It is hoped that additional transit trips from private automobile drivers deterred by congestion pricing due to the increased cost of driving will be attracted to transit. This in addition will retrofit the $\mathrm{CO}_{2}$ emission levels and congestion related challenges.

\section{Conclusions and recommendations}

The prevailing CMP system in Abuja, and its predict and provide engineering solution of road building and expansion has spur and fuel spatial growth towards suburbia. The development are not only not-aligned to transit corridor, they lack the density and diversity that represent decentralized employment area that can generate ridership to support transit operation. They are at best low density development that lay the city on its back and increase the distance between core- 
city employment area and suburban residential area and necessitate automobile dependent mobility pattern.

This study has illustrated that automobile dependent mobility pattern is indeed plagued with the challenges of $\mathrm{CO}_{2}$ emissions, traffic congestion and related man-hour and fuel wastage. Shift towards spatial planning strategies that focus on transit-dependent mobility, decentralization and aligning new development (TODs) along transit corridor present opportunity to transform sprawling cities to smart compact spatial form. This new transit-dependent regime will reduce automobile dependent travels and dwarf $\mathrm{CO}_{2}$ emission footprint, and traffic congestion challenges of fuel and man-hour wastage.

Thus, it is recommended that policy framework that is directed at leveraging existing urban planning institutions be evolved, so that spatial planning becomes institutionalized. As a result, synergistic framework emerges for sectoral integration (across sectors and stakeholders) required for implementing transitdependent mobility which will help to reduce transport-related $\mathrm{CO}_{2}$ emission footprint, and serve as climate change mitigation strategies, reduce traffic congestion challenges, and retrofit urban sprawl/suburbanization in Abuja.

\section{References}

[1] Molina, L. T., Molina, M. J., Slott, R. S., Kolb, C. E., Gbor, P. K., Meng, F., Singh, R. B., Galvez, O., Sloan, J. J., Anderson, W. P., Tang, X., Hu, M., Xie, S., Shao, M., Zhu, T., Zhang, Y. H., Gurjar, B. R., Artaxo, P. E., Oyola, P., Gramsch, E., Hidalgo, D., and Gertler, A. W.: Air Quality in Selected Megacities, Journal of the Air and Waste Management Association, 54:12, pp. 5, 2004.

[2] Schipper, L. J. and Marie-Lilliu, C., Carbon-dioxide Emissions from Transport in IEA Countries: Recent Lessons and Long-term Challenges Swedish Transport and Communications Research Board, Stockholm (Sweden) 1999-11, pp. 1, 1999

[3] Schipper, L. Marie-Lilliu, C. and Gorham, R., Flexing the Link between Transport and Greenhouse Gas Emissions: A Path for the World Bank International Energy Agency (IEA) Paris, pp. 9, 2000.

[4] Schipper, L. and Fulton, L.: Making Urban Transit Systems Sustainable Around the World. Transportation Research Record 1791 Paper No. 023573, pp. 44, 23, 2002.

[5] Dhakal, S. and Schipper, L., Transport and Environment in Asian Cities: Reshaping the Issues and Opportunities into a Holistic Framework. International Review for Environmental Strategies, Vol. 6 no. 2, 399-424. Institute for Global Environmental Strategies: Special Feature on the Environmental Sustainable City. pp. 12, 2006.

[6] Penalosa, E., Social and Environmental Sustainability in Cities in International Mayors Forum on Sustainable Urban Energy Development, Yunnan Province, China. pp. 1, 6-12, 2004.

[7] Williams K.: Spatial Planning, Urban Form and Sustainable Transport, Oxford Brookes University, UK, pp. 2-3, 2005. 
[8] Chin, N., Unearthing the Roots of Urban Sprawl: A Critical Analysis of Form, Function and Methodology Centre for Advanced Spatial Analysis, University College London, pp. 10, 2002.

[9] Kenworthy, J.R., The Eco-city: Ten Key Transport and Planning Dimensions for Sustainable City Development, SAGE, Australia. pp. 70, 2006.

[10] [10] United Nation Human Settlement Programme (UNHSP), Planning Sustainable Cities UK and USA: UN-HABITAT. pp.125, 154, 2009.

[11] Google Earth, 2012.

[12] Salingaros N. A., 'Compact City Replaces Sprawl' in Graafland A. and Kavanaugh L. (eds) Crossover: Architecture, Urbanism, Technology, Publishers, Rotterdam Holland, pp. 1, 2006.

[13] Institute for Transport and Development Policy (ITDP) and EMBARQ, The Life and Death of Urban Highways ITDP New York and EMBARQ, Washington, USA, pp. 5, 2012.

[14] Newman, P. and Kenworthy, J., The Ten Myths of Automobile Dependence, Journal of World Transport Policy and Practice, 6(1)15-25, pp. 23, 2000.

[15] Okon, I., Intra-city transportation and landuse planning in Nigeria: A case of Port Harcourt Metropolis, River State. Unpublished PhD research thesis, Department of Geography/Regional Planning, University of Calabar, pp. 2, 2008.

[16] Ball, M., Lets rethink the planning of Africa's urban areas $<$ www.informedinfrastructure.com/1488/let's-rethink-the-planning-ofafricas-urban-areas/>Accessed on 07/10/2012.

[17] The Royal Town Planning Institute (RTPI), Shaping and Delivering Tomorrow's Places: Efficient Practice in Spatial Planning. RTPI Publishers, UCL and Deloittee, London. pp. 9, 11, 83, 2007.

[18] Rydin, Y., The Purpose of Planning: Creating Sustainable Towns and Cities. The Policy Press, Bristol UK, pp. 33, 2011.

[19] United Nation Human Settltment Programme (UNHSP), Cities and Climate Change. UK and USA: UN-HABITAT, 2011.

[20] Hoornweg, D. Sugar, L. Lorena, C. Gomez T., Cities and Greenhouse Gas Emission: Moving Forward Environment and Urbanization Vol. XX No. X, 1-21, pp. 3-12, 2011.

[21] Beevers, D.S., and Carslaw, D.C., The Impact of Congestion Charging on Vehicle Emissions in London. Atmospheric Environment 39 (2005), p. 1-5, 2004.

[22] Federal Capital Development Authority (FCDA), The Master plan of Abuja the New Federal Capital of Nigeria, Published by I.P.A, pp. 2-5, 1979.

[23] Department of Treasury, Federal Capital Territory Administration (FCTA)/The National Assembly, Abuja, FCTA Statutory Capital Expenditure for years 2003-2008.

[24] FCT Transport Secretariat (2008)/Author (2011), Passenger and Vehicle Volumetric Count along AYA Route, Abuja.

[25] Author’s Field Survey, 2012. 
[26] Mickūnaitis, V., Pikūnas, A. and Mackoit, I., Reducing Fuel Consumption and $\mathrm{CO}_{2}$ Emission in Motor Cars, Transport, 22:3, 160-163, pp.160, 2007.

[27] Cervero, R. The Transit Metropolis: A Global Inquiry Island Press, Washington D.C. USA, pp. 285, 1998. 